\title{
Residues and Dissipation of Fenitrothion in Green Bean (Phaseolus vulgaris) and Soil
}

\author{
Farag Mahmoud Malhat \\ Department of Pesticide Residues and Environmental Pollution, Central Agricultural Pesticide Laboratory, \\ Agriculture Research Center, Dokki, Giza 12618, Egypt \\ Correspondence should be addressed to Farag Mahmoud Malhat, farag_malhat@yahoo.com
}

Received 6 December 2011; Accepted 5 January 2012

Academic Editor: D. Zhou

Copyright ( $\odot 2012$ Farag Mahmoud Malhat. This is an open access article distributed under the Creative Commons Attribution License, which permits unrestricted use, distribution, and reproduction in any medium, provided the original work is properly cited.

\begin{abstract}
The objective of this study were to determine the residue levels of fenitrothion in/on green bean pods, leaves, and soil under the treated plant and to identify the degradative metabolites of fenitrothion in soil under the treated plant. The results showed half-life $\left(t_{1 / 2}\right)$ values of $1.79,2.00$, and 6.08 days for fenitrothion in green bean pods, leaves, and soil, respectively. The results of GC-MS analysis of soil extracts under the treated plant showed that, at zero time, unchanged fenitrothion was found. The proportion of fenitrothion in soil extracts detected decreased with the time. GC-MS analysis of soil extracts shows the presence of compound having the formula of $\mathrm{C}_{7} \mathrm{H}_{7} \mathrm{NO}_{3}$ which is suggested to be 3-methyl-4-nitrophenol which is the major degrades of fenitrothion in soil. The other transportation products were not founded. According to the maximum residue limits (MRLs), the preharvest intervals (PHIs) of fenitrothion on green bean pods were 13 days after the treatment.
\end{abstract}

\section{Introduction}

Fenitrothion (O,O-dimethyl O-4-nitro-m-tolyl phosphorothioate) (Figure 1) is an organophosphorus insecticide. It is used against broad range of insects like Acrididae, wheat bugs chewing and sucking insects, leafminers, stemborer in rice, coffee, cotton, vegetables, potatoes, castors, and ornamental crops. Also used as household pesticide to control Hymenoptera, Siphonaptera, Culicidae, and so forth. Pesticide will continue to be used in the production of food and fiber especially in the developing countries. Nearly all these chemicals are readily soluble in plant oils and waxes; this common property places them all under suspicion as food contaminants. It is inevitable that, during pesticide application, varying amounts of these toxic substances reach adjacent vegetation, wildlife, soil, and water. Pesticides may possess different fates and behavior when they are released into the environment, and three primary modes of degradation are (a) biological breakdown by microorganisms, (b) chemical breakdown by chemical reactions, such as hydrolysis and redox reactions, and (c) photochemical breakdown by ultraviolet or visible light [1]. Once a pesticide has been introduced into the environment, its chemical and physical properties determine its fate: where it goes and how long it persists. Each pesticide has its own unique set of properties. Pesticides that break down quickly do not offer much opportunity for exposure. The degradation rate of a pesticide depends on the pesticides chemistry, as well as environmental factors, such as temperature, rainfall, and soil $\mathrm{pH}$ [2]. Pesticides are designed to be effective for a finite period to control pests and then break down to nontoxic substances. A pesticide that is adsorbed to or taken up into a plant is less likely to become a vapor, be washed off onto the soil, or be transferred to the skin if the plant is touched. The present work was initiated for (1) estimation of the total fenitrothion residue balance (residue in pods, leaves, and soil under the treated plant) in green bean after plant treatment at the recommended dosage for pest control and (2) identification of the degradative metabolites of fenitrothion in soil under the treated plant. 


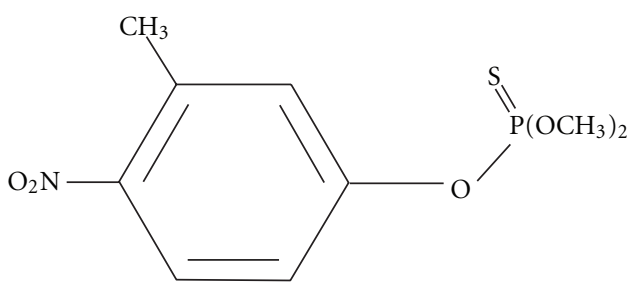

Figure 1: Chemical structure of fenitrothion.

\section{Materials and Methods}

All solvents were HPLC grade and supplied by Alliance Bio, USA. Celite 545, sodium sulfate anhydrate, and orthophosphoric acid (85\%) were purchased from El-Naser Pharmaceutical Chemical Company, Egypt. Analytical standard of fenitrothion (purity $\geq 99 \%$ ) was supplied by Sumitomo Chemical Company. A stock standard solution $(100 \mathrm{mg} / \mathrm{L})$ was prepared with ethyl acetate and stored at $-20^{\circ} \mathrm{C}$.

Green bean (Phaseolus vulgaris) was planted at ElMenofiya Governorate, Egypt, on 26 February 2005 in plots $\left(4 \times 10 \mathrm{~m}^{2}\right)$. The plots received the normal agronomic practices through the experimental period. Treatment was carried out by knapsack sprayer equipped with one nozzle. The commercial formulation Sumithion (50 fenitrothion $50 \%$ SC) was used. Three randomized plots were treated on 11 May 2005 by fenitrothion at the maximum dose recommended by the manufacturers ( $500 \mathrm{~g}$ a.i. per feddan), and one untreated plot was left to serve as control. The amount of formulated pesticide required for 1 feddan was diluted in $400 \mathrm{~L}$ of water. There was no rainfall at any time during the experimental period. The average daily temperature during the experiment was from 19 to $27^{\circ} \mathrm{C}$. Sampling was performed by randomly collecting from various places of the experimental plots according to the FAO/WHO [3] recommendations. Three replicate samples (about one $\mathrm{kg}$ each) were collected from pesticide-treated green bean pods, the leaves of the treated plant, and the soil under the treated plant. Samples were taken $2 \mathrm{~h}$ after the pesticide application. Subsequent samples were taken $1,3,6,9,12,15$, and 21 days after treatment. During experiment, a control sample was taken in each sampling time. Representative samples of treated or untreated soil were collected from the surface of the plots to a depth of $10 \mathrm{~cm}$ after $2 \mathrm{~h}, 1,3,6,12$, 19 , and 35 days after plant treatment. Immediately after collecting the samples, the samples were homogenized and subsampling was done where three representative samples of $50 \mathrm{~g}$ were taken. Samples were then placed into polyethylene containers and frozen at $-20^{\circ} \mathrm{C}$. The freezed subsamples were left to reach room temperature. Residues of fenitrothion were analyzed according to the technique developed by minstry of welfar, health and clutural affairs [4]. Residues were extracted from $50 \mathrm{~g}$ of green bean pods and the leaves of the treated plant with $150 \mathrm{~mL}$ of ethyl acetate and $50 \mathrm{~g}$ of anhydrous sodium sulfate using a warring blender and mixed for $10 \mathrm{~min}$ at high speed, then filtered through a dry pad of cotton and anhydrous sodium sulfate into a graduated cylinder. The extract was concentrated using a rotary evaporator at a rate below $35^{\circ} \mathrm{C} .50 \mathrm{~g}$ of the soil sample and $30 \mathrm{~g}$ anhydrous sodium sulfate were shaken mechanically with $200 \mathrm{~mL}$ of chloroform for $1 \mathrm{~h}$ in $500 \mathrm{~mL}$ stopper conical flask. The extract was carefully decanted and filtered through a clean pad of cotton. Known volume of extract was taken and evaporated to dryness. Aliquot of soil extract without cleanup was subjected to GC-MS analysis for identification of degradative metabolites. The plant and soil extracts were then cleaned up using the ammonium chloride solution and filtering through Celite 545 instead of hyflosupercell as suggested by Johnson [5]. The technique could be summarized as follows. The coagulation solution was prepared by dissolving $0.5 \mathrm{~g}$ of ammonium chloride and $1 \mathrm{~mL}$ of orthophosphoric acid $85 \%$ in $400 \mathrm{~mL}$ distilled water. A fresh solution was prepared daily. The residues were dissolved in $5 \mathrm{~mL}$ of methanol and thoroughly mixed with $10 \mathrm{~mL}$ of freshly prepared coagulating solution, and the contents were quantitatively transferred and filtered through a chromatographic column $(25 \mathrm{~mm}$ i.d. $\times 20 \mathrm{~cm}$ length $)$ packed with $2.5 \mathrm{~cm}$ layer of Celite 545 . Transfer was repeated four times using $5 \mathrm{~mL}$ of methanol and $10 \mathrm{~mL}$ of coagulating solution each. The filtrates were collected and partitioned three times with 30,25 , and $15 \mathrm{~mL}$ of dichloromethane using $125 \mathrm{~mL}$ separatory funnel. The combined dichloromethane layer was dried through anhydrous sodium sulfate and then evaporated to dryness using a rotary evaporator at a rate below $35^{\circ} \mathrm{C}$. The residues were dissolved in a proper volume of ethyl acetate for GC analysis. The rate of degradation $(K)$ and half-life $\left(t_{1 / 2}\right)$ values were obtained from the following equation of Gomaa and Belal [6]:

$$
\begin{gathered}
\text { Rate of degradation }(K)=2.303 \times \text { slope, } \\
\text { Half-life }\left(t_{1 / 2}\right)=\frac{0.693}{K}
\end{gathered}
$$

The extracts were concentrated and injected into a gas liquid chromatography (Hewlett-Packard Model 6890) equipped with a flam photometric detector GC/FPD. GC analysis was conducted on a PAS-1701 (Agilent, Folsom, CA) fused silica capillary column of $30 \mathrm{~m}$ length, $0.32 \mathrm{~mm}$ id., and $0.25 \mu \mathrm{m}$ film thickness. The oven temperature was programmed from an initial temperature 180 ( $2 \mathrm{~min}$ hold) to $240^{\circ} \mathrm{C}$

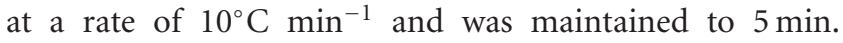
Injector and detector temperature were maintained at 240 and $260^{\circ} \mathrm{C}$, respectively. Nitrogen was used as a carrier at flow rate of $3 \mathrm{~mL} / \mathrm{min}$. Hydrogen and air flow rate were 75 and $100 \mathrm{~mL} / \mathrm{min}$, respectively. Peak was identified by comparison of sample retention time value with those of the corresponding to pure standard compound. GC-MS analyses were performed with an Agilent 6890 gas chromatograph equipped with an Agilent mass spectrometric detector with a direct capillary interface and fused silica capillary column HP-5MS ( $30 \mathrm{~m} \times 320 \mu \mathrm{m} \times 0.25 \mu \mathrm{m}$ film thickness $)$. Helium was used as carrier gas at approximately $1.0 \mathrm{~mL} / \mathrm{min}$. The solvent delay was $3 \mathrm{~min}$. A $1 \mu \mathrm{L}$ sample was injected into the GC using splitless mode. The injector was operated at $250^{\circ} \mathrm{C}$. The column temperature was maintained at $80^{\circ} \mathrm{C}$ for $3 \mathrm{~min}$ and then programmed at $8^{\circ} \mathrm{C} / \mathrm{min}$ to $260^{\circ} \mathrm{C}$ and held to $5 \mathrm{~min}$. The mass spectrometric detector was operated in 
TABLE 1: Recoveries and relative standard deviations for fenitrothion on green bean pods, leaves, and soil at various fortification levels.

\begin{tabular}{lccccr}
\hline $\begin{array}{l}\text { Fortified level (mg/kg) } \\
(n=3)^{*}\end{array}$ & \multicolumn{2}{c}{ Green bean pods } & \multicolumn{2}{c}{ Leaves } & \multicolumn{2}{c}{ Soil } \\
\hline 0.1 & Recovery & RSD & Recovery & RSD & Recovery \\
0.5 & 89.79 & 7.10 & 80.00 & 11.02 & 99.20 \\
1 & 87.20 & 4.56 & 84.50 & 5.69 & 96.00 \\
\hline$*$
\end{tabular}

${ }^{*} n$ : number of samples.

TABLE 2: Dissipation of fenitrothion residues $\left(\mathrm{mg} \mathrm{kg}^{-1} \pm \mathrm{SD}\right)$ in/on green bean pods and leaves.

\begin{tabular}{|c|c|c|c|c|}
\hline \multirow[b]{2}{*}{ Time (days) } & \multicolumn{2}{|c|}{ Green bean pods } & \multicolumn{2}{|c|}{ Leaves } \\
\hline & $\begin{array}{l}\text { Residue level } \\
(\text { mean } \pm \mathrm{SD})\end{array}$ & Dissipation \% & $\begin{array}{l}\text { Residue level } \\
(\text { mean } \pm \mathrm{SD})\end{array}$ & Dissipation \% \\
\hline Zero & $21.728 \pm 0.381$ & 0.00 & $80.04 \pm 1.151$ & 0.00 \\
\hline 1 & $10.018 \pm 0.415$ & 53.89 & $38.192 \pm 0.694$ & 52.28 \\
\hline 3 & $3.84 \pm 0.765$ & 82.32 & $9.782 \pm 0.113$ & 87.77 \\
\hline 6 & $0.836 \pm 0.243$ & 96.15 & $5.776 \pm 0.096$ & 92.78 \\
\hline 9 & $0.396 \pm 0.192$ & 98.17 & $1.228 \pm 0.002$ & 98.46 \\
\hline 12 & $0.129 \pm 0.127$ & 99.40 & $0.68 \pm 0.050$ & 99.15 \\
\hline 15 & $0.061 \pm 0.021$ & 99.71 & $0.43 \pm 0.007$ & 99.46 \\
\hline 21 & ${ }^{*} \mathrm{ND}$ & - & ND & - \\
\hline MRL & 0.1 & & - & \\
\hline$k\left(\right.$ days $\left.^{-1}\right)$ & 0.385 & & 0.345 & \\
\hline$t_{1 / 2}$ (days) & 1.79 & & 2.00 & \\
\hline
\end{tabular}

* Not detectable.

electron impact ionization mode with an ionizing energy of 70 e.v. scanning from $\mathrm{m} / \mathrm{z} 50$ to 500 . The ion source temperature was $320^{\circ} \mathrm{C}$ and the quadruple temperature $150^{\circ} \mathrm{C}$. The electron multiplier voltage was maintained $1050 \mathrm{v}$ above autotune.

Untreated samples of green bean pods, the leaves of the plant, and soil were spiked with known amounts of fenitrothion prior to extraction and cleaning up for recovery tests. These samples were passed through the entire process of extraction then cleaned up and analyzed as previously described. Recovery assays were performed in the 0.1$1 \mathrm{mg} \mathrm{kg}^{-1}$ range. At each fortification level, three replicates were analyzed. Results of recovery are presented in Table 1.

Data were statistically evaluated by one-way analysis of variance (ANOVA). All statistical analyses were done using the statistical package for social sciences (SPSS 16.0) program.

\section{Results and Discussion}

Data in Table 2 indicate the amount of fenitrothion residues in green bean pods at different intervals after applications. The initial deposit of fenitrothion was $21.728 \mathrm{mg} / \mathrm{kg}$ on and in green bean pods. The residue amount decreased to $10.018 \mathrm{mg} / \mathrm{kg}$ on and in green bean pods after one day of applications. The residues of this insecticide dropped to 3.84, $0.836,0.396,0.129$, and $0.061 \mathrm{mg} / \mathrm{kg}$ on green bean pods after $3,6,9,12$, and 15 days from treatment, respectively. The calculated half-life value of this insecticide was 1.79 days on green bean pods. The first day after application showed to be critical in the residue degradation rates. According to FAO/WHO Codex Alimentarius commission [7], the maximum residue limits (MRLs) on green bean pods were $0.1 \mathrm{ppm}$. The recommended preharvest interval (PHI) was 13 days after application of fenitrothion on green bean plants. Also, the data in Table 2 demonstrate that the initial deposits of fenitrothion on and in green bean leaves were $80.04 \mathrm{mg} / \mathrm{kg}$, at one hour after application. These values rapidly dropped to $38.192 \mathrm{mg} / \mathrm{kg}$ indicating the rate of loss $52.28 \%$ of the initial deposits 1 day after treatment. Following that period, fenitrothion residues on and in green bean leaves decreased to $9.782,5.775,1.228,0.680$, and $0.430 \mathrm{mg} / \mathrm{kg}$ at $3,6,9,12$, and 15 days after application, respectively. The leaves of green bean samples taken 21 days after treatment contained no detectable amounts of fenitrothion. The residue half-life value of fenitrothion on the leaves of green bean was 2 days. These results indicated the direct relationship between the application rates of pesticides, formulation type, and the residual concentration determined on and in the plant. Many investigators concluded that the applied concentration and formulation type of the pesticide, the physical and living state of the plant surface, the relation between the treated surface and its weight, in addition to the environmental condition are the most effective factors on the initial deposits of the pesticides $[8,9]$.

The data in Table 3 showed that the initial deposit of fenitrothion residue was $2.882 \mathrm{mg} / \mathrm{kg}$ in soil under green bean plant, while after one day the residues decreased to $2.105 \mathrm{mg} / \mathrm{kg}$. Fenitrothion residues were $1.055 \mathrm{mg} / \mathrm{kg}$ at 3 
TABLE 3: Dissipation of fenitrothion residues $\left(\mathrm{mg} \mathrm{kg}^{-1} \pm \mathrm{SD}\right)$ in soil under the treated plant.

\begin{tabular}{lcc}
\hline Time $($ days $)$ & Residue level $($ mean \pm SD) & Dissipation $\%$ \\
\hline Zero & $2.882 \pm 0.128$ & 0.00 \\
1 & $2.105 \pm 0.067$ & 26.96 \\
3 & $1.055 \pm 0.045$ & 63.56 \\
6 & $0.803 \pm 0.072$ & 72.13 \\
12 & $0.543 \pm 0.101$ & 81.16 \\
19 & $0.267 \pm 0.023$ & 90.73 \\
35 & $* \mathrm{ND}$ & - \\
$k$ (days $\left.^{-1}\right)$ & 0.113 & \\
$t_{1 / 2}$ (days $)$ & 6.08 & \\
\hline
\end{tabular}

${ }^{*}$ Not detectable.

days after application and then decreased to $0.803,0.543$, and $0.267 \mathrm{mg} / \mathrm{kg}$ after 6,12 , and 19 days from application in soil under green-bean-treated plants, respectively. The residue half-life value of fenitrothion on the soil under green bean plants was 6.08 days.

The results showed that, at zero time, unchanged fenitrothion was found when analyzed by GC-MS. The proportion of fenitrothion in soil extracts detected by GCMS decreased by the time. The mass spectrum show a molecular ion peak at $\mathrm{m} / \mathrm{z} 153$ and fragment 136, 108, $90,77,63,53$, and 46 which correspond to the formula $\mathrm{C}_{7} \mathrm{H}_{7} \mathrm{NO}_{3}$ which is suggested to be 3-methyl-4-nitrophenol which is the major degrades of fenitrothion in soil. The other transportation products were not founded. The results of this study indicated that fenitrothion is mainly degraded via cleavage of the P-O-aryl linkage and then further breakdown occurs. The results of this study are in agreement with those obtained by Yeomans and Swales [10] who studied the route and rate of degradation of (phenyl- ${ }^{14} \mathrm{C}$ ) fenitrothion and found that fenitrothion is mainly degraded via cleavage of $\mathrm{P}-\mathrm{O}$-aryl linkage and then further breakdown occurs, via opening of the phenyl ring, with eventual mineralization to ${ }^{14} \mathrm{CO}_{2}$.

\section{References}

[1] G. Gruzdyev, V. Zinchenko, V. Kalinin, and R. Slovtsov, The Chemical Protection of Plants, Mir Publishers, New York, NY, USA, 1983.

[2] J. Sanz-Asensio, M. Plaza-Medina, and T. Martinez-Soria, "Kinetic study of the degradation of ethiofencarb in aqueous solutions," Pesticide Science, vol. 50, no. 3, pp. 187-194, 1997.

[3] FAO/WHO, Recommended Methods of Sampling for Determination of Pesticide Residues Part 6, vol. 8, 2nd edition, 1986.

[4] Analytical Methods for Residues of Pesticides in Food Stuff, Ministry of Welfare, Health and Cultural Affairs, The Hague, The Netherlands, 1988.

[5] D. P. Johnson, "Determination of sevin insecticide residues in fruit and vegetables," Journal of the Association of Official Agricultural Chemists, vol. 46, no. 2, pp. 234-237, 1963.

[6] E. Gomaa and M. Belal, "Determination of dimethoate residues in some vegetables and cotton plant," Zagazig Journal of Agricultural Research, vol. 2, pp. 215-219, 1975.
[7] FAO/WHO, "Codex Alimentarious Commission, Pesticide Residues in Food. Maximum Residues Limit," 2009.

[8] M. M. Almaz, Residues of some pesticides on some plants of medical importance, Ph.D. thesis, Faculty of Agriculture, Moshtohor, Zagazig University, Zagazig, Egypt, 1985.

[9] S. Khay, J. Choi, and M. Abd El-Aty, "Dissipation behavior of lufenuron, benzoyphenylurea insecticide, in/on Chines cabbage applied by foliar spraying under greenhouse condition," Bulletin of Environmental Contamination and Toxicology, vol. 81, pp. 369-372, 2008.

[10] P. Yeomans and S. Swales, " $\left({ }^{14} \mathrm{C}\right)$-fenitrothion: soil metabolism and degradation. Sumitomo chemical Co. ref. no. HM0192," Tech. Rep. 333/148-D2142. GLP, Covance Laboratories, Harrogate, North Yorkshire, UK, 2001. 

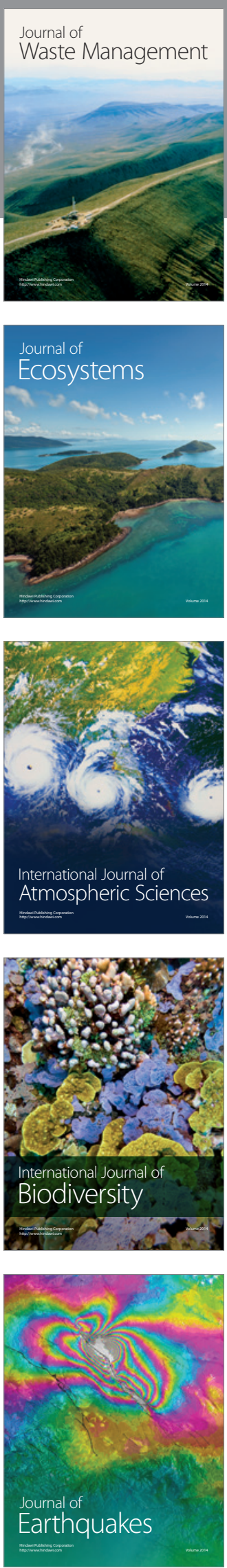
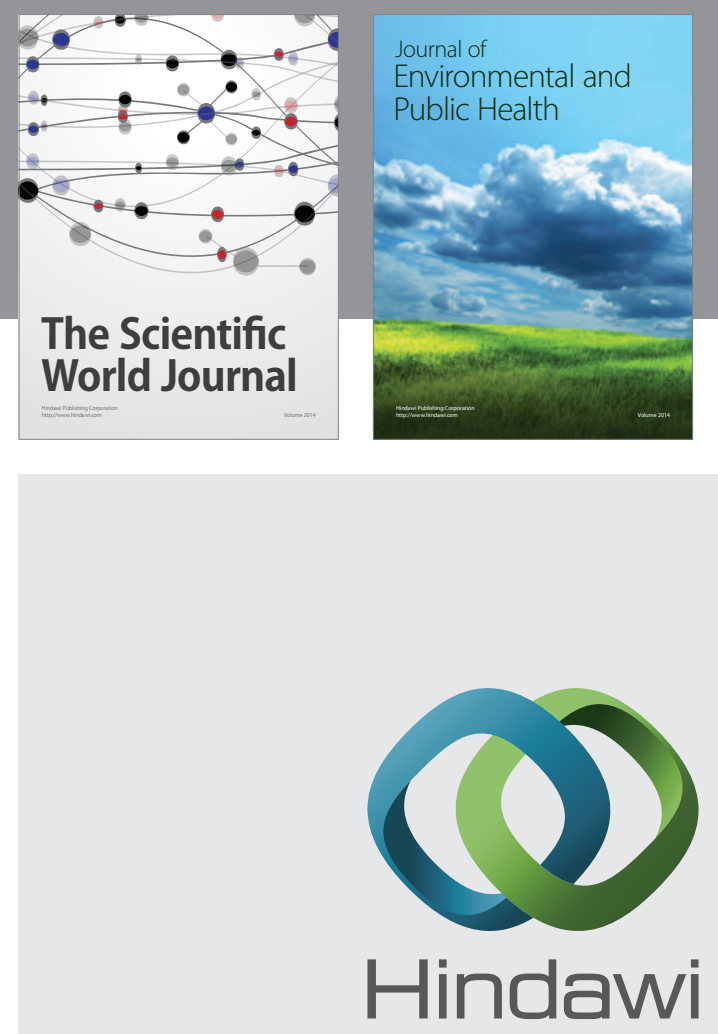

Submit your manuscripts at

http://www.hindawi.com
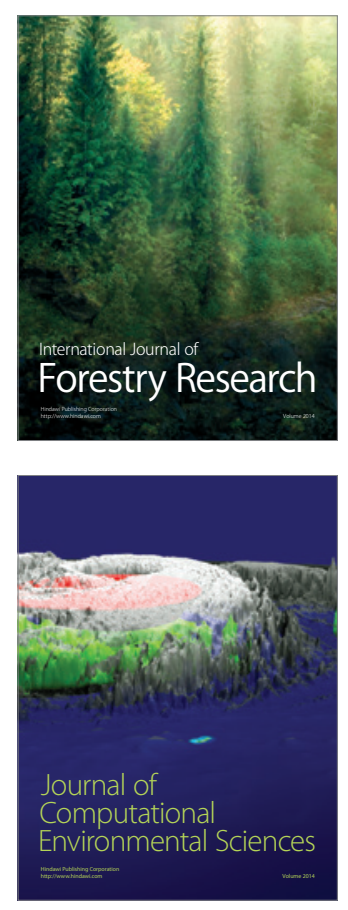
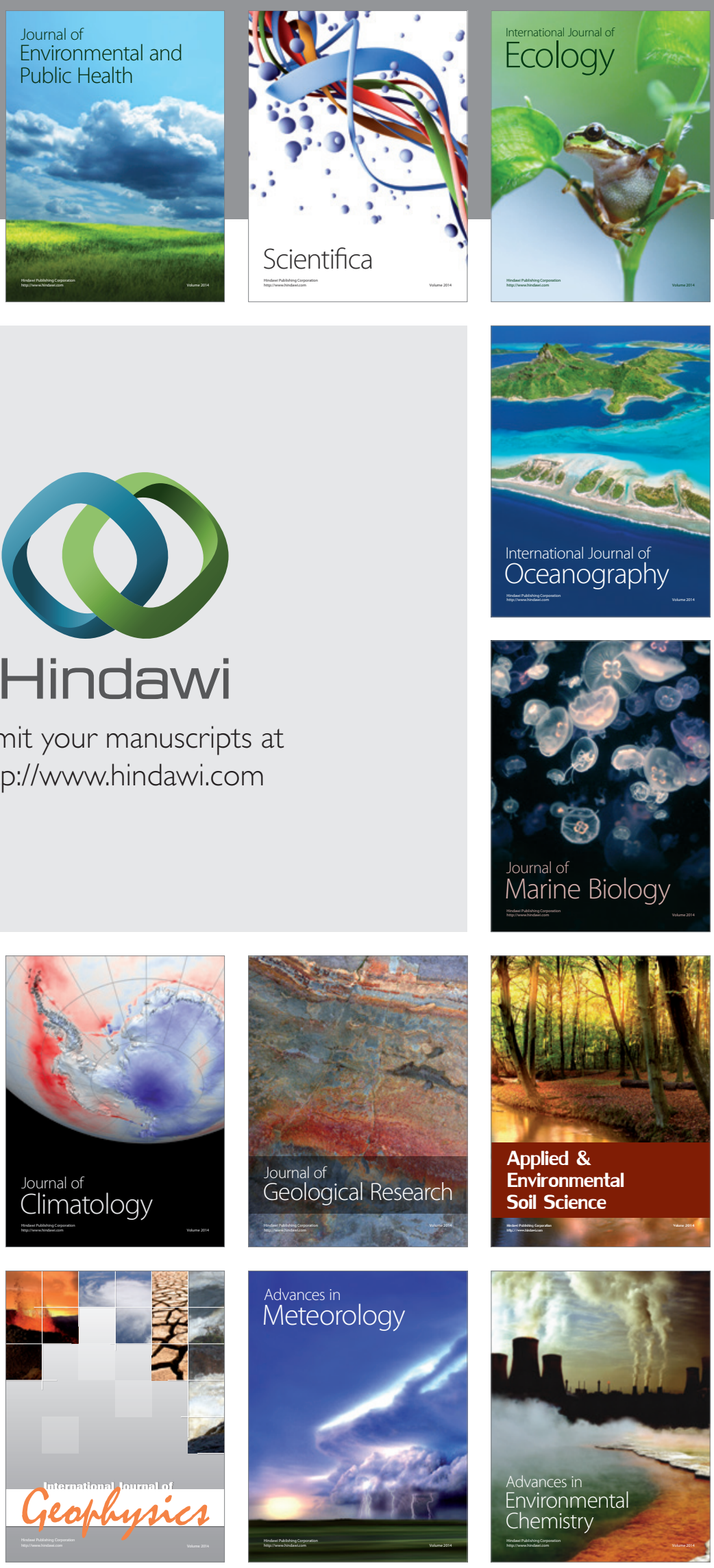